\title{
Impact of Harvest Equipment on Ash Variability of Baled Corn Stover Biomass for Bioenergy
}

\author{
Ian J. Bonner • William A. Smith • Jeffery J. Einerson • \\ Kevin L. Kenney
}

Published online: 1 March 2014

(C) The Author(s) 2014. This article is published with open access at Springerlink.com

\begin{abstract}
Cost-effective conversion of agricultural residues for renewable energy hinges not only on the material's quality but also the biorefinery's ability to reliably measure quality specifications. The ash content of biomass is one such specification, influencing pretreatment and disposal costs for the conversion facility and the overall value of a delivered lot of biomass. The biomass harvest process represents a primary pathway for accumulation of soil-derived ash within baled material. In this work, the influence of five collection techniques on the total ash content and variability of ash content within baled corn stover in southwest Kansas is discussed. The equipment tested included a mower for cutting the corn stover stubble, a basket rake, wheel rake, or shred flail to gather the stover, and a mixed or uniform in-feed baler for final collection. The results showed mean ash content to range from 11.5 to $28.2 \%$ depending on operational choice. Resulting impacts on feedstock costs for a biochemical conversion process range from $\$ 5.38$ to $\$ 22.30 \mathrm{Mg}^{-1}$ based on the loss of convertible dry matter and ash disposal costs. Collection techniques that minimized soil contact (shred flail or nonmowed stubble) were shown to prevent excessive ash contamination, whereas more aggressive techniques (mowing and use of a wheel rake) caused greater soil disturbance and entrainment within the final baled material. Material sampling and testing were shown to become more difficult as within-
\end{abstract}

I. J. Bonner $(\bowtie) \cdot$ K. L. Kenney

Biofuels and Renewable Energy Technologies Department, Idaho

National Laboratory, Idaho Falls, ID, USA

e-mail: ian.bonner@inl.gov

W. A. Smith

Biological Systems Department, Idaho National Laboratory, Idaho Falls, ID, USA

\section{J. J. Einerson}

Human Factors, Controls, and Statistics Department, Idaho National Laboratory, Idaho Falls, ID, USA bale ash variability increased, creating uncertainty around feedstock quality and the associated costs of ash mitigation.

Keywords Corn stover $\cdot$ Biomass $\cdot$ Bales $\cdot$ Ash $\cdot$ Soil contamination

\section{Introduction}

Agricultural residues are anticipated to account for one quarter to one half of the available biomass supply for use within the emerging bioenergy and bioproducts industry [1]. Corn stover, the residue remaining after grain harvest comprised stalks, leaves, husks, and cobs, is one such feedstock made attractive because of existing availability and collection infrastructure [2]. As with all lignocellulosic feedstocks, the quality of the material is crucial for a commercially viable conversion platform. Numerous specifications have been identified as biomass quality metrics, including moisture content, material composition, and ash [3]. Of the major feedstock specifications, ash content has received special attention due to problems of slagging, fouling, and corrosion in thermochemical conversion processes and displacement of fermentable carbohydrate and potential buffering capacity during pretreatment in biochemical conversion, which increase operational costs for both processes [3-5]. If the amount of ash accompanying biomass is highly variable, the costs of pretreatment, handling, and disposal will become increasingly uncertain. To maintain the quality of feedstocks for combustion or liquid fuel conversion, the amount of soil entering delivered feedstock must be minimized and controlled.

Unless measured at the time of receipt, the mass of ash is accounted for in biomass yield, skewing the perceived amount of convertible dry matter [3]. This additional soil-derived ash must then be disposed of, either through preprocessing prior to material treatment or as waste following any number of steps 
throughout the conversion process. According to the National Renewable Energy Laboratory, the predicted transportation and disposal cost of ash from boiler operations within a biochemical conversion plant is $\$ 31.8 \mathrm{Mg}^{-1}$ [6]. A review by Kenney et al. [7] estimated that a $5 \%$ increase in soilderived ash would increase a $227 \mathrm{ML}_{\text {year }}{ }^{-1}$ conversion facility's costs by $\$ 1.15 \mathrm{M}$ year $^{-1}$, which translates to a $1 \%$ increase in the minimum ethanol selling price of $\$ 0.57 \mathrm{~L}^{-1}$ (in 2007 US dollars). To reduce the magnitude and uncertainty of these costs, the variability and total amount of ash delivered to the biorefinery should be minimized.

The ash content of biomass has been documented for a number of crop types, with hand-harvested whole plant corn stover typically in the range of 5-7\% [4, 8-11] and singlepass corn stover (usually lacking lower stalk) as low as $2-4 \%$ $[12,13]$. Although the intrinsic ash content of different crops can vary widely (from less than $1 \%$ in pine chips to over $15 \%$ for rice hulls [14]), elevated ash levels are commonly attributed to soil contamination during harvest and collection [11, 15-18]. Traditional multipass collection of corn stover involves several steps where the material comes into contact with soil. The mechanical processes of spreading, mowing, windrowing, and baling subject the biomass to ground contact, increasing the likelihood of entraining soil within the baled material. Additionally, the fraction of plant collected and the type of soil on which material is harvested influences the final ash content of a feedstock [13, 17, 19]. Shinners et al. [20] showed the ash content of corn stover from single-pass, two-pass, and multipass operations to range from 4 to 6 to $10 \%$, respectively, clearly demonstrating the importance of ground contact on final feedstock ash content. While the lowash benefit of advanced harvesting systems such as single pass has been well documented for corn stover, information on more common multipass equipment choices and their relation to ash content is currently lacking.

The purpose of this study was to determine the influence of multipass harvest methods (stubble treatment, windrow operation, and baler selection) on variability and total ash content of baled corn stover as a result of soil contamination within a controlled case study in southwest Kansas. Bales created using five collection methods were sampled intensively and analyzed for total ash. This work presents an understanding of the spatial distribution and variability of ash within conventional multipass bales originating from a single region. Additionally, the results presented provide a comparison of each system's performance in terms of bulk ash content and the impact of these measures on bale sampling, feedstock specification certainty, and ultimately the cost to a biorefinery.

\section{Methods and Materials}

\section{Biomass and Sampling}

Corn stover was collected from three fields in Stevens County, KS in October, 2011. Each of the fields consisted primarily of Belfon and Canina loam soils of slopes less than $2 \%$. A total of five equipment combinations were operated by a contract harvesting team to collect and bale the stover into standard $0.91 \mathrm{~m} \times 1.22 \mathrm{~m} \times 2.44 \mathrm{~m}$ rectangular format. The combinations of equipment were based on (1) stubble treatment, (2) windrow method, and (3) baler collection/formation method. Stubble treatment was applied on a whole-field basis, where one field remained intact following harvest of grain by a combine with an ear-snapper corn header, the second field was mowed, and the third field was treated with a shred flail. Windrow and baler selection were then applied to the appropriate fields based on the combinations listed in Table 1. Corn stover collection rates for the three fields were 4.2, 3.8, and 3.2 $\mathrm{Mg} \mathrm{ha}^{-1}$ for the nonmowed, mowed, and shred flail fields, respectively. Based on the average 2011 corn grain harvest for the county [21] and a grain to residue ratio of 0.8:1 [22], it is estimated that approximately $7.25 \mathrm{Mg} \mathrm{ha}^{-1}$ of residue was available at each of the fields; this initial basis results in an estimated harvest collection efficiency of $58 \%$ for the nonmowed field, $52 \%$ for the mowed field, and $44 \%$ for the shred flail field.

The equipment used included a Land Pride RCM 5020 rotary mower (Great Plains Manufacturing, Salina KS) for reducing stubble height, a CropLogix Windrower 20 center discharge shredder (Loftness Manufacturing, Hector MN) for reducing stubble height and collecting the material into

Table 1 Equipment and field combinations for each sampling treatment

\begin{tabular}{|c|c|c|c|c|c|c|}
\hline $\begin{array}{l}\text { Stubble } \\
\text { treatment }\end{array}$ & $\begin{array}{l}\text { Windrow } \\
\text { operation }\end{array}$ & $\begin{array}{l}\text { Baler } \\
\text { in-feed handling }\end{array}$ & $\begin{array}{l}\text { Baler } \\
\text { pre-compression }\end{array}$ & $\begin{array}{l}\text { Treatment } \\
\text { code }\end{array}$ & $\begin{array}{l}\text { Total cores } \\
\text { collected }\end{array}$ & $\begin{array}{l}\text { Field harvest } \\
\text { rate }\left(\mathrm{Mg} \mathrm{ha}^{-1}\right)\end{array}$ \\
\hline Mowed & Basket rake & Uniform & No & MBU & 234 & $3.8^{\mathrm{a}}$ \\
\hline Nonmowed & Basket rake & Uniform & No & NMBU & 270 & 4.2 \\
\hline Mowed & Wheel rake & Uniform & No & MWU & 270 & $3.8^{\mathrm{a}}$ \\
\hline Mowed & Basket rake & Mixed & Yes & MBM & 234 & $3.8^{\mathrm{a}}$ \\
\hline Shred flail & N/A & Uniform & No & SU & 216 & 3.2 \\
\hline
\end{tabular}

${ }^{\text {a }}$ Each of the three mowed treatments were performed on a single field for which total yield was assessed 
windrows, a R2800 TwinRake twin-basket rake (Vermeer Manufacturing, Pella IA) and VR1428 High-Capacity wheel rake (Vermeer Manufacturing, Pella IA) for windrowing the stover when applicable. To test the influence of material handling within the baler on ash content, two balers with differing material feeds and bale compression designs were chosen. A Freeman Model 1592 Big Baler (Allied Systems Company, Duluth GA) that uses a uniform in-feed handling and no material pre-compression was compared against a Hesston 2170 large square baler (AGCO Corporation, Duluth GA) that uses a mixed in-feed handling system and forms flakes in a pre-compression chamber before being inserted into the bale chamber. The combination of mowed stubble, basket rake, and uniform in-feed baler was used as the base case, with one of the operations changed in each subsequent treatment group. Table 1 details the collection technique, treatment code, and number of samples collected from each treatment.

Bales from each condition were created only on the fields of respective stubble treatment, and thus across-field variability was not measured by this study. Additionally, within-field variability (i.e., the potential for influential surface features or operator variation) was not actively controlled in this work, though it was assumed that bales from the mowed treatment (which were all created on a single 49 ha field) were more heavily influenced by equipment choice than field specific conditions. To aid in this assumption, each of the three treatments within the mowed condition were performed adjacent to one another, such that no one treatment occupied an isolated area of the field. In an industrial feedstock supply system, both across- and within-field variability sources will likely influence a region's average ash content and the relationship between equipment selection and ash content. While such questions must be addressed, the work presented here is not intended to define an all-inclusive operational average for the equipment types used. Instead, this research targets the influence of equipment selection on ash content and ash variability within baled corn stover in a case-specific instance where multiple equipment types may be utilized by a producer or harvester.

Six bales were selected from each equipment combination and sampled using a $50 \mathrm{~mm} \times 200 \mathrm{~mm}$ coring tool. Core samples were collected on a grid pattern across the bale as shown in Fig. 1. Five sampling planes were designated along the length of the bale with a total of nine sampling locations on each plane for a total of forty-five sample locations per bale. Plane-1 represented the tail-end of the bale, or the first material to enter the baler, while plane- 5 represented the head of the bale, or the last material to enter the baling chamber. Loss of the ability to retrieve the central cores from planes 2-4 midway through sample collection reduced the number of cores collected in three of the treatments, as reflected in the total core count in Table 1. Nevertheless, due to the large number of samples collected, including six cores in planes $2-4$, this incident was not detrimental to the affected condition's data analysis.

\section{Testing and Analysis}

Core samples were ground using a laboratory knife-mill with a 2-mm screen. Duplicate aliquots of approximately $1 \mathrm{~g}$ (recorded to $0.1 \mathrm{mg}$ ) were taken from each sample and analyzed for ash by loss on ignition at $575{ }^{\circ} \mathrm{C}$ [23]. Ash content was calculated using Eq. 1:

$\%$ Ash $=($ Mass of Ash/Mass of Biomass $) \times 100$

The mean of the duplicate ash values was used to define each core's ash content. Weighted mean ash content was determined for each treatment by using the relative frequency of values occurring within $2.5 \%$ histogram bins. To investigate spatial trends within the bales, the ash data was translated onto a 3D coordinate system based on each core's location within the bale. SAS software (SAS Institute Inc, Cary NC) was used to test for correlation between geometric location and ash within each bale and within each group of bales [24].

To understand the influence of collection technique on bulk ash content and the role of ash variability on sampling uncertainty, statistical bootstrapping and Monte Carlo simulation were performed using Microsoft Excel (2007; Microsoft Corp, Redmond WA). The bootstrap analysis was performed with 1,000 iterations while the Monte Carlo simulation was performed with 100 iterations at each test interval. More detail on each of these analyses as well as any assumptions and operational details are discussed at length in the "Results and Discussion."

\section{Results and Discussion}

\section{Spatial Distribution of Ash}

The most crucial, and often most overlooked, aspect of measuring biomass quality is obtaining a representative sample. The intensive sampling method employed here was used to generate ash distribution profiles across all three dimensions of the sampled bales. These profiles were then evaluated to determine if ash was randomly or systematically distributed due to the mechanical action of the baling equipment. For example, it was originally hypothesized that the residence time within the baling chamber would influence ash distribution as the repeated pounding of the baler's plunge would cause soil to settle downward within the bale, resulting in both a vertical and lengthwise patterned distribution of ash. If any such occurrences were factual, bale sampling procedures 
Fig. 1 Sampling diagram for $0.91 \mathrm{~m} \times 1.22 \mathrm{~m} \times 2.44 \mathrm{~m}$ rectangular corn stover bales with nine sampling locations per plane

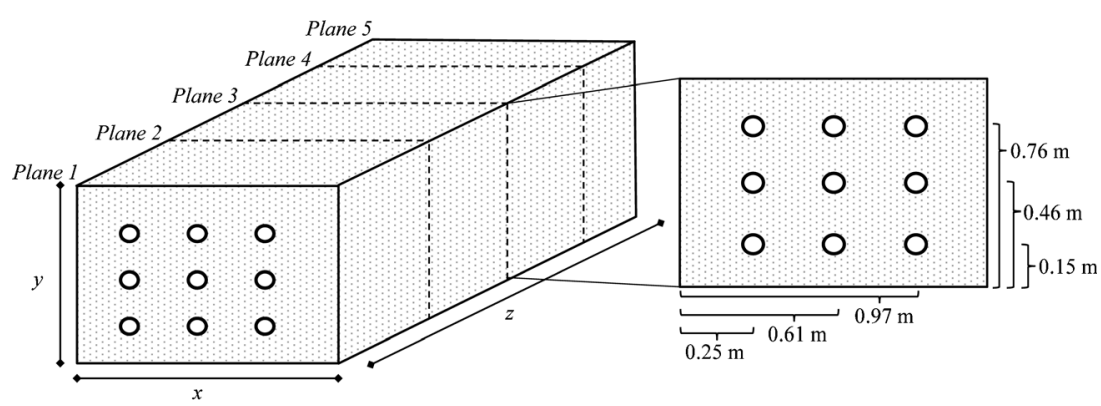

would have to take these patterns into account to avoid bias and properly represent the bulk conditions.

The spatial variability in ash content was modeled by fitting a Gaussian process response surface for the ash content by the three dimensions of a bale; width (X, $\mathrm{m}$; left to right), height (Y, m; bottom to top), and length ( $\mathrm{Z}, \mathrm{m}$; head to tail). Analysis of variance was performed to partition the total variability of ash content into variability by dimension. This included partitioning the main effects $(\mathrm{X}, \mathrm{Y}$, and $\mathrm{Z})$ as well as first-order interactions of the dimensions. Table 2 presents the results for each equipment combination. Each entry in the table is the percent of total variability explained by each dimension and first-order interaction. For example, the variability in ash content for the wheel rake treatment (MWU) is highest in the $\mathrm{Y}$ direction (61.2\%), some in the $\mathrm{X}$ direction $(37.5 \%)$, and a small interactive effect between $\mathrm{X}$ and $\mathrm{Y}$ $(1.3 \%)$. This is graphically shown in Fig. 2 where dimension profiles for each equipment combination illustrate the contribution of dimension to the total variability.

Two important conclusions are made from the spatial variability analysis. First, there does not appear to be any significant pattern to the location of ash in these bales, supporting the practice of random sampling and compositing to obtain representative bulk ash content. This is evident in Fig. 2 by the relatively constant ash content across any dimension. For example, from bottom to top (Y direction; 0.13 to $0.89 \mathrm{~m}$,

Table 2 Variability partitioning of ash content (percentage of total variability by dimension)

\begin{tabular}{|c|c|c|c|c|c|c|}
\hline \multirow[t]{2}{*}{ Treatment } & \multicolumn{3}{|c|}{ Main effect } & \multicolumn{3}{|c|}{ Interaction } \\
\hline & $X$ & $\mathrm{Y}$ & Z & $\mathrm{X}$ and $\mathrm{Y}$ & $\mathrm{X}$ and $\mathrm{Z}$ & $\mathrm{Y}$ and $\mathrm{Z}$ \\
\hline NMBU & $58.0 \%$ & $39.4 \%$ & 0 & $2.6 \%$ & 0 & 0 \\
\hline $\mathrm{MBU}$ & 0 & $8.9 \%$ & $90.3 \%$ & 0 & 0 & $0.8 \%$ \\
\hline MBM & $36.6 \%$ & $48.2 \%$ & $5.0 \%$ & $8.6 \%$ & $0.4 \%$ & $1.2 \%$ \\
\hline MWU & $37.5 \%$ & $61.2 \%$ & 0 & $1.3 \%$ & 0 & 0 \\
\hline SU & 0 & $100.0 \%$ & 0 & 0 & 0 & 0 \\
\hline
\end{tabular}

$N M B U$ nonmowed, basket rake, uniform in-feed, $M B U$ mowed, basket rake, uniform in-feed, $M W U$ mowed, wheel rake, uniform in-feed, $M B M$ mowed, basket rake, mixed in-feed, $S U$ shred flail, uniform in-feed respectively), there is little change in mean ash content. The largest change in the Y direction occurred for the MWU but was less than $4 \%$. These results also show that any withinfield variability caused by influential spatial conditions such as irregular soil surfaces was not significant, as indicated by the lack of correlation between ash content and $\mathrm{Z}$ direction and the consistent confidence interval $(\mathrm{CI})$ surrounding this measure. If site-specific conditions had impacted only certain bales or certain conditions as they were collected over an influential portion of the field, it would be expected that the $\mathrm{CI}$ surrounding the $\mathrm{Z}$ direction would have been nonuniform and/or large as well as variable in magnitude across the treatments. The relatively small uncertainty surrounding the mean ash content of the bales tested in the $\mathrm{Z}$ direction again supports that random sampling and compositing can be a reliable method for bulk ash measurement under the conditions tested. Secondly, the analysis clearly demonstrates that the shred flail treatment (SU) was the equipment combination with the lowest total ash content as well as the least amount of variability.

\section{Core Sample Ash Content}

Each of the five equipment combinations exhibited noticeable differences in ash content and variability (Fig. 3). The box and whisker plot depicts the distribution of each treatment's complete set of samples. The bar within the box represents the median ash content (second quartile) and the bottom and top ends of the box represent the inter quartile range (first and third quartiles (IQR)). The length of the whiskers depicts the lowest and highest data points within 1.5 IQR below or above the first and third quartiles, respectively.

The lowest measured ash value for each of the treatments ( $5.8 \% \pm 0.6 \%$; mean \pm 1 standard deviation) is in agreement with the average of $5.6 \%$ for "clean" whole plant corn stover reported by others [9-11, 18], evidence that the elevated ash content of the majority of core samples is due to soil contamination. Several important trends relating to the influence of equipment combination on bale ash content can be interpreted from the grouped datasets for each treatment. The distribution of ash for the mowed-stubble, basket rake, uniform in-feed baler base treatment (MBU) showed $74 \%$ of all cores to 

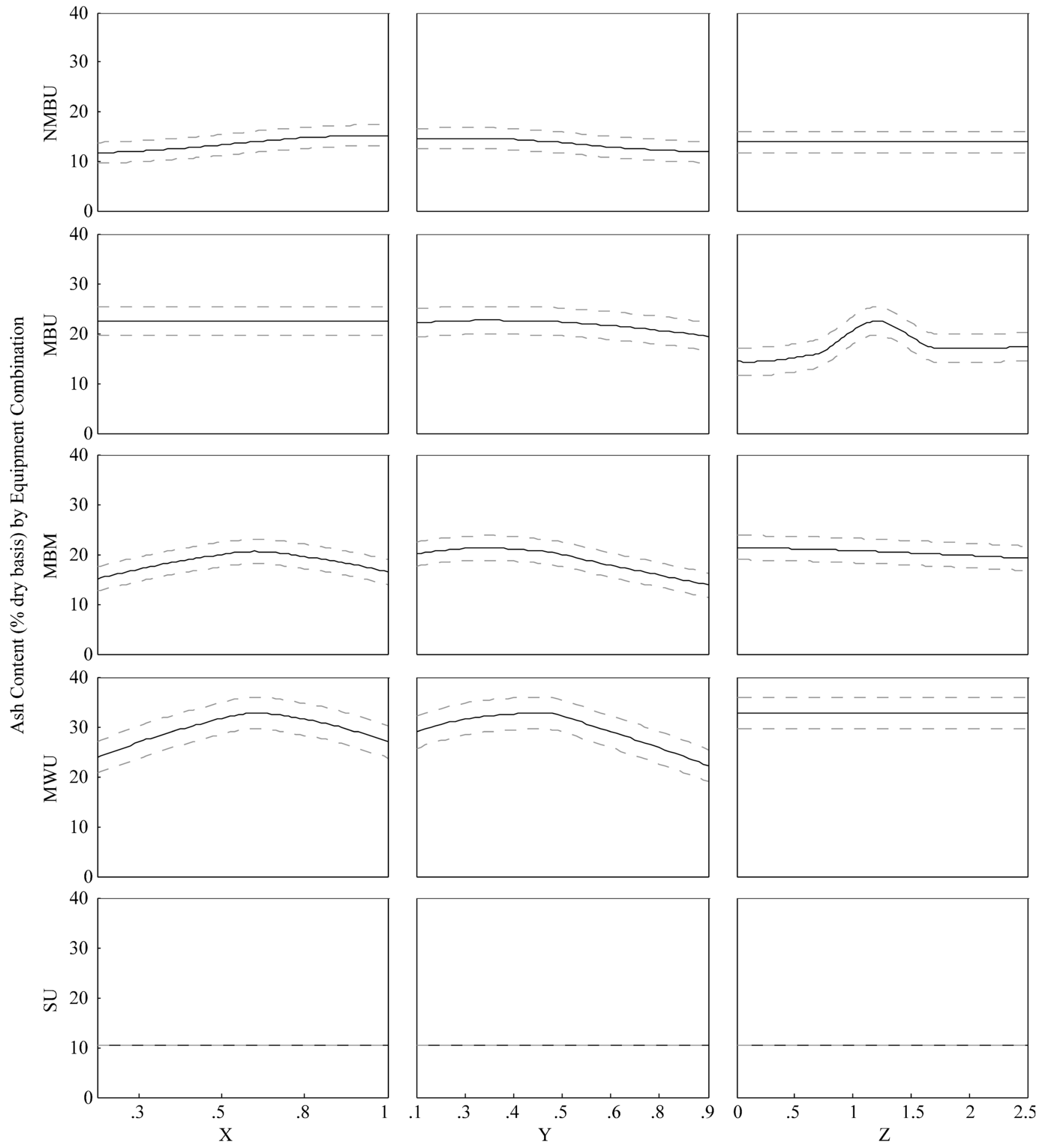

Bale Dimension, meters

Fig. 2 Ash content variability profiles by bale dimension; dashed lines represent the $95 \% \mathrm{CI}$ of the mean. $N M B U$ nonmowed, basket rake, uniform in-feed, $M B U$ mowed, basket rake, uniform in-feed, $M W U$

contain $<20.0 \%$ ash. The remaining samples spanned from 22 to $75 \%$ ash, indicating that localized pockets of high soil contamination occurred within the bales. While these high values had little impact on the bulk ash content of the bale, mowed, wheel rake, uniform in-feed, $M B M$ mowed, basket rake, mixed in-feed, $S U$ shred flail, uniform in-feed

their presence created large uncertainties; the standard deviation of the combined set of samples was $9.5 \%$.

The nonmowed treatment using the basket rake and uniform in-feed baler (NMBU) showed a unique occurrence 


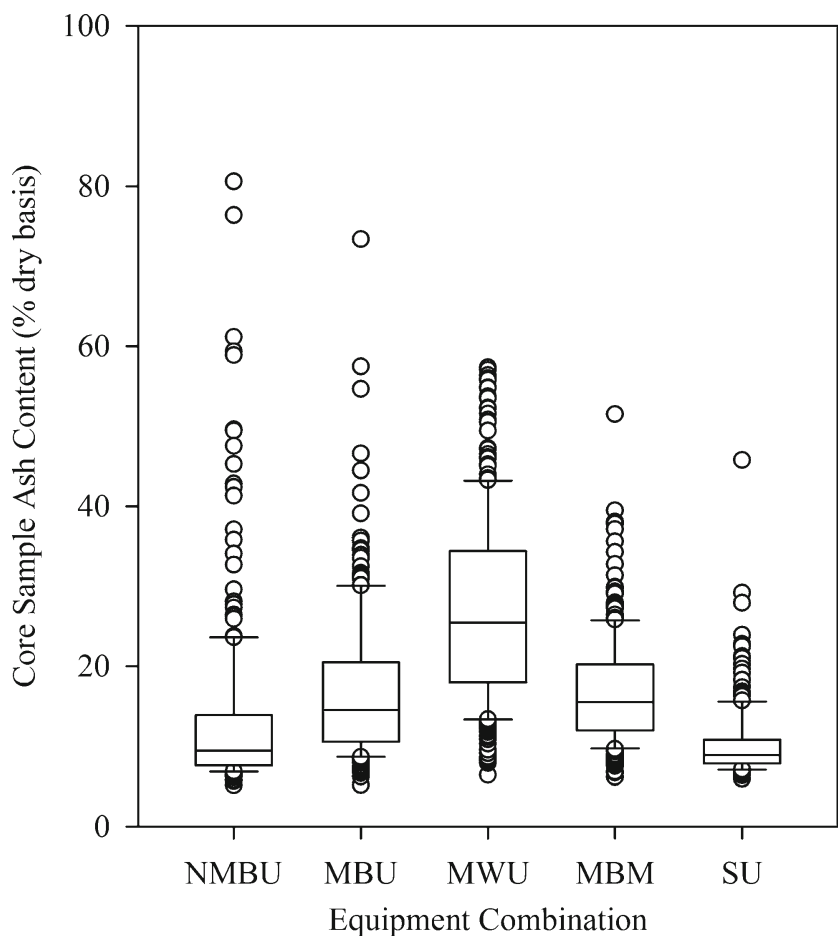

Fig. 3 Box plot distribution of all core samples collected for each equipment combination. $N M B U$ nonmowed, basket rake, uniform infeed, $M B U$ mowed, basket rake, uniform in-feed, $M W U$ mowed, wheel rake, uniform in-feed, $M B M$ mowed, basket rake, mixed in-feed, $S U$ shred flail, uniform in-feed

amongst the treatments. The root mass attached to incompletely severed stalks was observed to be pulled from the soil and placed in the windrow. These large clots of soil, termed "rootballs" (Fig. 4) were then incorporated into the bales. Albeit in low frequency, the presence of these root-balls resulted in core samples with extremely high ash contents (five of the core samples collected measured between 60 and $80 \%$ ash). Despite this unique handicap, the nonmowed treatment resulted in $54 \%$ of the core samples to contain $\leq 10 \%$ ash and $87 \%$ of all cores $\leq 20 \%$ ash; the second best performance out of all five treatments. Relative to the MBU, this finding suggests that leaving stubble intact increased the frequency of root-ball related high ash samples (38\% increase in relative occurrence of core samples above $40 \%$ ash), but lowered the amount of loose soil in the windrow, causing bulk ash content of the bales to decrease $(14.7 \%$ versus $18.3 \%$ weighted mean ash content, respectively). Additionally, it is possible that the nonmowed treatment resulted in bales with lower quantities of lower stalk, a fraction of the plant that has been repeatedly shown to have higher ash content than the upper stalk [13, 19]. The nonmowed treatment appears advantageous in terms of lowering bulk ash content, but the potential for uncertainty in mean measurements may be skewed high due to the presence of root-balls.

When comparing wheel rake to basket rake windrowing methods on the mowed field with a uniform in-feed baler

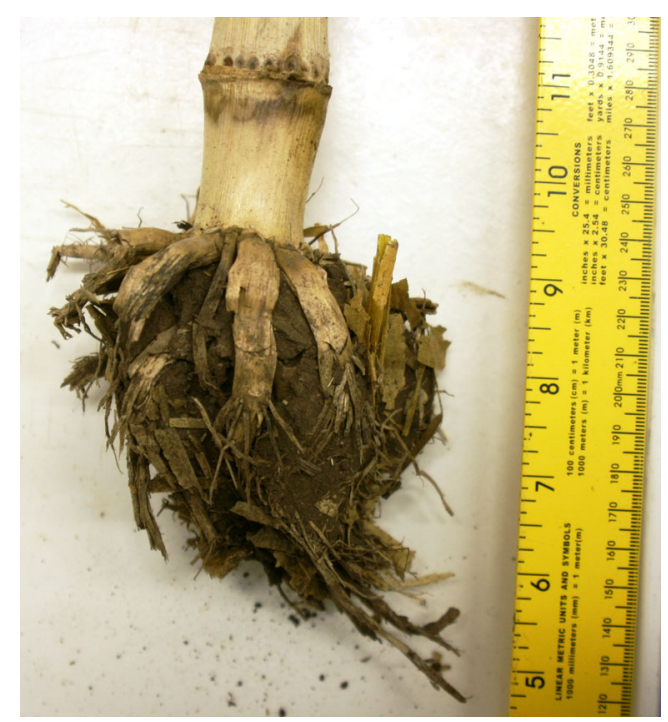

Fig. 4 Corn stover root mass and soil collected from the windrow of the nonmowed treatment

(MWU), the weighted mean ash content was extremely elevated at $28.2 \% ; 10 \%$ greater than that of the basket rake treatment (MBU). Only $31 \%$ of the wheel raked core samples were $\leq 20 \%$ ash, and the distribution of the samples appeared to approach normality with a long flat distribution nearly centered on the weighted mean, however, the distribution still failed to pass standard normality tests (Shapiro-Wilk; $P<0.001)$. From the results of this work, the practice of windrowing with a wheel rake had a large negative impact on soil entrainment in corn stover bales. This is most likely explained by the different drive systems of each of the windrowers, with the ground-driven wheels causing greater soil disturbance and transfer than the hydraulically driven and suspended forks of the twin-basket rake.

The tests comparing baler type (uniform in-feed versus mixed in-feed) showed a slight shift in sample ash distribution. The mixed in-feed treatment (MBM) had a lower frequency of samples between $6 \%$ ash and $13 \%$ ash, and higher frequency of samples between $15 \%$ and $25 \%$ ash than the MBU. These subtle differences were not enough to influence the bulk ash content however, as both balers resulted in weighted mean ash contents of $18 \%$. It is possible that the nonuniform distribution of tines in the mixed in-feed baler caused stover with high soil contamination to tumble and disperse loose soil amongst the relatively clean stover, creating a comparatively more even distribution of ash within the final bale than the uniform in-feed baler.

The shred flail treatment with uniform in-feed baler (SU) showed the most dramatic impact on bale ash content compared with the MBU. Over $67 \%$ of the samples collected were $\leq 10 \%$ ash and $95 \%$ of cores were $\leq 20 \%$ ash. This impressive shift in sample distribution resulted in a weighted mean ash content of $11.5 \%$. By tightening the distribution, the uncertainty of sampling was decreased, dropping the standard 
deviation across all cores to $4.5 \%$, down from $9.5 \%$ for the base MBU treatment. This suggests that the removal of a raking step by shredding reduced ground contact and soil entrainment into the windrowed material, similar in principal to the reduced ash content of single and two-pass bales reported by Shinners et al. [20]. Morissette et al. [18] showed small square bales created from a shred flail windrower in the spring to have an average ash content of only $5.9 \%$ with an upper range of $9.3 \%$, suggesting that further improvement may be possible if delayed collection time and reduced yield are viable tradeoffs for improving quality. To this affect, it should be noted that the shred flail field resulted in the lowest yield of the three tested, potentially aiding its increased performance insofar as soil contamination is concerned (Table 1). Nevertheless, of the conditions tested, the shred flail combination provided the most desirable results, and would be recommended in similar soil conditions when bale soil contamination is of primary concern.

\section{Bootstrap Analysis}

The broad distribution of core sample ash values caused high standard deviations and wide CIs surrounding the mean ash content of each treatment group. Bootstrapping (random resampling of the original ash values) was used to improve the sample estimates of the mean and variance of each treatment. The results of this analysis allow the mean ash content of each equipment combination to be easily viewed and distinguished from one another (Fig. 5). All five of the bootstrap mean predictions resulted in normal distributions (Shapiro-Wilk; $P>0.15$ ) with the SU, NMBU, and MWU treatments being clearly separated from the MBU) and no difference between the two baler types (MBM versus MBU). However, the complete sample set remains unable to satisfy normality and equal variance assumptions required for a typical parametric analysis of variance. Instead, the Kruskal-Wallis one way analysis of variance on ranks was used to conclude that the differences in the median values of equipment combination were statistically different $(P<0.001)$. Post hoc testing found statistically significant differences between each equipment combination
(Tukey; $P<0.05$ ) with the exception of the comparison between the uniform in-feed and mixed in-feel balers (MBU versus MBM; Tukey; $P>0.05$ ). These results support the above discussed conclusions of the core-to-core and spatial variability testing, specifically that the field treatment and windrowing operation had a measurable impact on mean ash content, but baler choice did not.

The variability of ash within treatment type is shown through the $95 \%$ CI surrounding the bootstrap mean. Treatments with cores at or above $40 \%$ ash (nonmowed, mowed, and wheel raked; NMBU, MBU, and MWU, respectively) had greater $95 \%$ CIs $(0.08,0.08$, and $0.09 \%$, respectively) than those with few or no cores greater than $40 \%$ ash (shred flail and mixed in-feed baler; SU and MBM; 0.06 and $0.04 \%$ respectively). The impact of the few extremely high ash content cores on within treatment variability is certainly measurable but has low representative weight against the calculated mean.

\section{Monte Carlo Simulation}

Bulk ash content has an easily understood impact on feedstock quality and potential mitigation costs, but this research has shown accurate measurement of this metric to be quite difficult. As bale heterogeneity increased, ash determination through core collection caused core-to-core variability to rise dramatically, resulting in large variance estimates. If measurement methods for ash are unable to detect differences in bale quality, payout and management of feedstock will be forced to deal with high uncertainty; both in material value (grower payment) and material quality (conversion performance). To better understand this issue, a Monte Carlo simulation was performed to measure the impact of sampling intensity on the resulting mean ash measurement. Based on the abovediscussed analysis of spatial variability, randomly sampling from any position within bales is supported over any sort of systematic collection. The analysis assumed 11 hypothetical truckloads of bales were delivered to the biorefinery based on available corn stover yields, bale densities, and truck capacities for one 160 acre "quarter section" [25]. Bales on each
Fig. 5 Distribution of bootstrap mean values, $n=1,000$. $N M B U$ nonmowed, basket rake, uniform in-feed, $M B U$ :mowed, basket rake, uniform in-feed, $M W U$ mowed, wheel rake, uniform infeed, $M B M$ mowed, basket rake, mixed in-feed, $S U$ shred flail, uniform in-feed

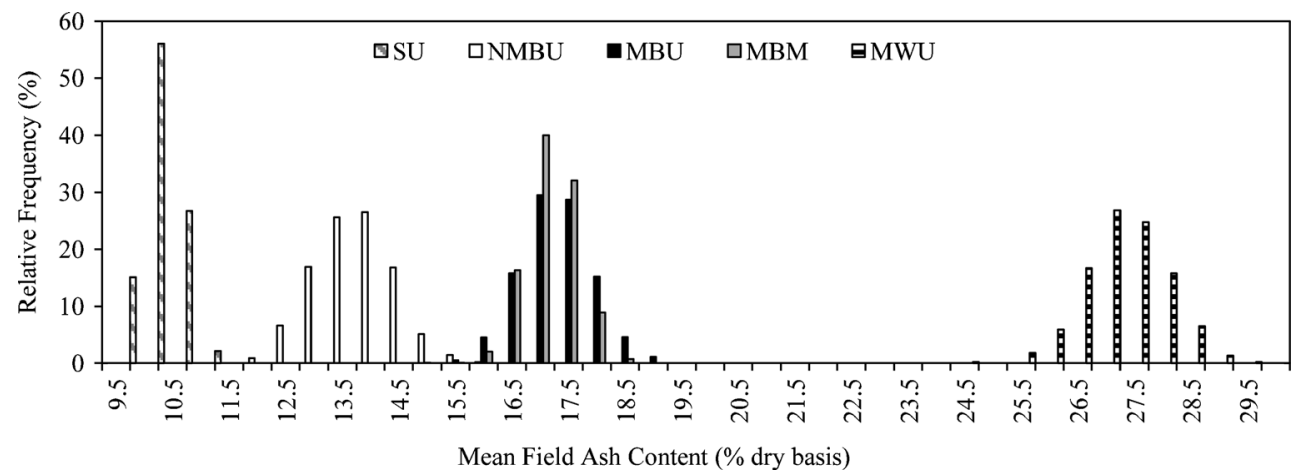


truck were assigned equal variance defined by the variability of the samples collected in this study. By sampling a fixed number of randomly collected cores from each of the 11 trucks and compositing all core samples taken per truck (as would likely be done in a mixing, grinding, and subsampling analysis at point of sale), 11 samples $(n=11)$ is always achieved regardless of the number of cores taken per truck. These 11 values were then averaged to calculate a single mean ash content and $95 \%$ CI based on 100 iterations of the simulated event.

As would be expected, the results of the simulation showed the $95 \%$ CI surrounding the mean to improve with the number of cores taken, however, the magnitude of uncertainty and rate of change differed between each equipment combination (Fig. 6). The NMBU and MWU treatments had the largest CI and lowest rate of change as the number of cores per truck increased, despite contrasting one another in terms of mean ash content. Both of these treatments required ten cores per truck to reach a $95 \% \mathrm{CI}$ near $2 \%$. The MBU base case fell in the mid-range for the size of its CI, but showed a noticeable decease by seven cores per truck. The high level of uncertainty in NMBU, MWU, and MBU treatments was due to the increased likelihood of retrieving samples with ash contents greater than $40 \%$. While the mean ash content of MBM was not significantly different than MBU, the reduced number of samples above $40 \%$ ash caused a notable difference in the confidence of the estimate of the mean. By five cores per truck MBM reached a $95 \%$ CI of $<2 \%$ ash, compared with the seven cores required by the MBU base case to reach similar levels of confidence. The SU combination outperformed all others, with a $95 \% \mathrm{CI}$ of $<2 \%$ by only two cores per truck.

In terms of effort-in versus accuracy-out, a $95 \% \mathrm{CI}$ of $1.5 \%$ was selected as a hypothetical benchmark to compare each of the five treatment groups. To meet this requirement the SU collection method would require three cores samples per truck, MBM would require seven core samples per truck, and NMBU, MBU, and MWU treatments would all require more than 15 cores per truck. Keeping in mind sample volume, collection time, and handling time across 11 trucks, it is likely that the three cores required by the SU combination would be the only reasonable lot of bales to sample within the selected CI of $1.5 \%$. This exercise clearly shows the advantage of reducing ash heterogeneity by preventing introduction of soil into bales.

\section{Impact of Ash Contamination on Feedstock Cost}

The impacts of soil-derived ash include: (1) mass displacement of fermentable biomass resulting in decreased ethanol yields ( $\mathrm{L} \mathrm{Mg}^{-1}$ dry matter), and (2) accumulation of ash onsite resulting in increased waste disposal costs. The first of these impacts assumes that ash content is included in the delivered feedstock's dry matter payout, where dry matter is composed of both fermentable biomass and nonfermentable components, including ash. Under this assumption, the value of a feedstock (where value is represented by non-ash biomass) decreases proportionally to increasing ash content. For example, for 1 million $\mathrm{Mg}$ of biomass purchased at $10 \%$ ash, $100,000 \mathrm{Mg}$ of the purchased product would have no value. This waste-ash fraction would need to disposed of as well as replaced by additional biomass if the intended production of the originally purchased 1 million $\mathrm{Mg}$ is to be achieved. The cost of ash contamination was estimated for each of the equipment combinations using the operational costs and parameters established by Humbird et al. [6] in their 2011 biochemical conversion design report. The cost impact of ash in this analysis includes both replacement costs - the cost of replacing ash with a proportionate mass of convertible biomass - and disposal costs. The Humbird design report assumed a delivered feedstock cost of $\$ 64.49 \mathrm{Mg}^{-1}$, an ethanol yield of $330 \mathrm{~L} \mathrm{Mg}^{-1}$, and an ash disposal costs of $\$ 31.81 \mathrm{Mg}^{-1}$ for a model feedstock containing $5 \%$ ash. These assumptions establish the baseline for comparing the cost impact of our corn stover harvest scenarios, such that only the ash content above $5 \%$ results in additional ash disposal and feedstock replacement. The $95 \%$ CIs obtained from the hypothetical sampling condition of three cores per truck for each equipment combination were used as the basis for calculating the CIs around feedstock replacement and ash disposal costs. A $95 \%$ CI of $1.5 \%$ ash was used for the baseline

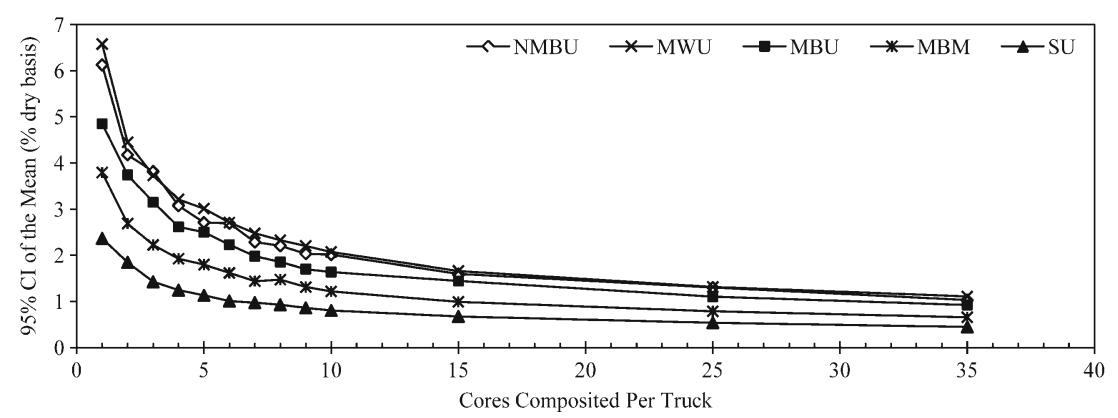

Fig. 6 Monte Carlo estimation of the $95 \%$ CI surrounding the mean ash content of bales as sampling intensity is increased. $N M B U$ nonmowed, basket rake, uniform in-feed, $M B U$ mowed, basket rake, uniform in-feed,
$M W U$ mowed, wheel rake, uniform in-feed, $M B M$ mowed, basket rake, mixed in-feed, $S U$ shred flail, uniform in-feed ash content 
case. Cost increases were calculated and expressed as an additional dollars per megagram of feedstock delivered above the baseline case necessary to maintain a fixed annual ethanol production of $230 \mathrm{ML}_{\text {year }}{ }^{-1}$.

A feedstock replacement scheme was based on the assumption that an increasing ash concentration displaces convertible biomass components. This in turn lowers the effective ethanol yield of the received materials, dropping from the baseline of 330 to $253 \mathrm{~L} \mathrm{Mg}^{-1}$ in the case of the wheel rake equipment combination (Table 3). This decrease in yield requires more feedstock to maintain the $230 \mathrm{ML}_{\text {year }}{ }^{-1}$ production goal. Annual feedstock requirements increase by 41,000 to $211,000 \mathrm{Mg}$ above the baseline of $700,000 \mathrm{Mg}$ year $^{-1}$ across the five equipment combinations tested (Table 3). The cost of obtaining this biomass - at equal quality - would increase annual feedstock purchase costs by $\$ 2.7$ to $\$ 13.6 \mathrm{M}$ year $^{-1}$ (Table 3). Dividing the annual replacement cost by the total annual quantity of biomass for each of these scenarios equates to a $\$ 3.60$ to $\$ 14.93 \mathrm{Mg}^{-1}$ increase in feedstock cost.

The increased feedstock demand and consumption of soil contaminated biomass results in higher accumulation of onsite ash. The equipment combinations shown here would result in an additional 41,000 to $211,000 \mathrm{Mg}$ of ash produced per year compared with the baseline (Table 3). Ash is assumed to be a waste requiring off-site disposal at the cost of $\$ 31.81 \mathrm{Mg}^{-1}$ for transportation and landfill fees [6]. Disposal costs for the ash generated by each treatment ranged from $\$ 1.3$ to $\$ 6.7 \mathrm{M}$ year $^{-1}$ above the baseline case (Table 3). Dividing the annual waste disposal cost by the total annual quantity of biomass for each of these scenarios equates to a $\$ 1.78$ to $\$ 7.37 \mathrm{Mg}^{-1}$ increase in feedstock cost.

The total impact of each equipment combination's feedstock replacement and waste disposal costs range from $\$ 5.38$ to $\$ 22.30 \mathrm{Mg}^{-1}$ (Table 3). The SU treatment (5.3\% ash above the baseline of $5 \%$ ) would equate to an increase of $\$ 5.38 \mathrm{Mg}^{-1}$ if mean ash content was measured accurately (Table 3). Using the benchmark of three cores per truck, this would increase the uncertainty of the feedstock replacement and ash disposal costs by $\pm \$ 1.50 \mathrm{Mg}^{-1}$. To contrast this value, the MWU combination (22\% soil contamination) would result in additional feedstock costs of $\$ 22.30 \pm \$ 4.66 \mathrm{Mg}^{-1}$ when sampled at only three cores per truck. The remaining three equipment combinations have calculated increases on feedstock cost of $\$ 9.11 \pm \$ 4.21 \mathrm{Mg}^{-1}, \$ 12.28 \pm \$ 3.55 \mathrm{Mg}^{-1}$, and $\$ 12.09 \pm \$ 2.48 \mathrm{Mg}^{-1}$ for the NMBU, MBU, and MBM, respectively (Table 3 ).

This analysis has made the assumption that above-baseline ash content, if not measured at the point of sale, will be inadvertently purchased at feedstock price. As the true cost of ash becomes understood, it is likely that rapid-screening methods will be implemented by refineries to determine a lot's ash content at the time of purchase. The refinery would then be capable of paying out on only the valuable non-ash fraction of the feedstock, as is currently done with moisture content correction, and would thereby pass off the costs of replacement and disposal to the supplier. This type of feedstock payment system would effectively transfer the added feedstock production cost presented in Table 3 to the supplier as a dockage fee. For the equipment combinations tested here, this

Table 3 Ash contents and economic impact on a biochemical conversion process, including increases to annual and feedstock costs

\begin{tabular}{|c|c|c|c|c|c|c|}
\hline & \multicolumn{6}{|c|}{ Equipment combination } \\
\hline & Baseline & NMBU & $\mathrm{MBU}$ & MWU & MBM & SU \\
\hline Mean ash content $(\%)$ & $5.0(1.5)$ & $14.0(3.8)$ & $17.1(3.2)$ & $27.0(3.7)$ & $16.9(2.2)$ & $10.3(1.4)$ \\
\hline Effective ethanol yield ${ }^{\mathrm{a}}\left(\mathrm{L} \mathrm{Mg}^{-1}\right)$ & $330(5)$ & $298(13)$ & $288(11)$ & $253(13)$ & $288(8)$ & $311(5)$ \\
\hline Feedstock $^{\mathrm{b}}\left(\mathrm{Gg}_{\text {year }}{ }^{-1}\right)$ & $700(11)$ & $774(36)$ & $803(32)$ & $912(49)$ & $801(22)$ & $742(12)$ \\
\hline Ash waste $\left(\mathrm{Gg}\right.$ year $\left.^{-1}\right)$ & $35(11)$ & $108(30)$ & $137(25)$ & $246(34)$ & $135(18)$ & $76(11)$ \\
\hline Feedstock cost ${ }^{\mathrm{c}}\left(\$ \mathrm{M}\right.$ year $\left.^{-1}\right)$ & $45.2(0.7)$ & $49.9(2.3)$ & $51.8(2.0)$ & $58.8(3.2)$ & $51.7(1.4)$ & $47.8(0.8)$ \\
\hline Ash disposal $\operatorname{Cost}^{\mathrm{d}}\left(\$ \mathrm{M}\right.$ year $\left.{ }^{-1}\right)$ & $1.1(0.3)$ & $3.4(0.9)$ & $4.4(0.8)$ & $7.8(1.1)$ & $4.3(0.6)$ & $2.4(0.3)$ \\
\hline Effective added cost ${ }^{\mathrm{e}}\left(\$ \mathrm{Mg}^{-1}\right)$ & $-(1.51)$ & $9.11(4.21)$ & $12.28(3.55)$ & $22.30(4.66)$ & $12.09(2.48)$ & $5.38(1.50)$ \\
\hline
\end{tabular}

Values enclosed in parenthesis are $95 \%$ confidence interval

$N M B U$ nonmowed, basket rake, uniform in-feed, $M B U$ mowed, basket rake, uniform in-feed, $M W U$ mowed, wheel rake, uniform in-feed, $M B M$ mowed, basket rake, mixed in-feed, $S U$ shred flail, uniform in-feed

${ }^{\text {a }}$ Corrected for ash displacement of fermentable biomass

${ }^{\mathrm{b}}$ Assuming a $230 \mathrm{ML}$ annual ethanol production facility adjusted for effective yield [6]

${ }^{\mathrm{c}}$ Assuming $\$ 64.49 \mathrm{Mg}^{-1}$ [6]

${ }^{\mathrm{d}}$ Assuming $\$ 31.81 \mathrm{Mg}^{-1}[6]$

${ }^{\mathrm{e}}$ Based on feedstock replacement due to decreased ethanol yield and ash disposal costs 
would translate to a feedstock payment as low as $\$ 42.19 \mathrm{Mg}^{-1}$ in the case of the wheel rake bales; a $35 \%$ reduction in payment. This type of financial repercussion may have severe impacts on grower participation as well as provide an incentive for proper equipment selection based on a particular region's performance. Although these values are specific to this dataset, the examples continue to stress the importance of soil contamination and heterogeneity on downstream costs within the biomass logistics system. Note that these calculations are only for biomass replacement and waste disposal costs for the soil-derived ash. Additional costs associated with soil contamination include reduced pretreatment efficiency, equipment wear/maintenance, and fouling/slagging. With these points in mind, it is easy to imagine production costs far exceeding those based solely on replacement and ash disposal costs.

\section{Conclusions}

The results of this research have shown ash variability within baled corn stover to be heavily impacted by equipment choice, with operations that cause greater ground disturbance resulting in increased soil contamination. The bulk ash content of bales should remain a primary concern for collection equipment choice as it will ultimately be an issue for the biorefinery's conversion and operating costs. While the equipment performance measured in this work is specific to the local conditions of soil type, slope, texture, and composition, the findings of this work strongly support conventional collection systems that minimize soil disturbance. As a result of this, reduction of bale heterogeneity by minimizing localized soil contamination will allow sampling and feedstock grading to be much more easily accomplished, creating confidence for downstream operational costs.

In terms of soil distribution and bulk soil contamination of baled corn stover, these results suggest the shred flail field treatment is superior to nonmowed and mowed fields in terms of reducing bale ash content, reducing variability within bales, and simplifying sampling procedures. This finding is of additional benefit as it eliminates an in-field operation, reducing collection costs and time while improving biomass quality. The choice of a uniform in-feed or mixed in-feed baler would likely have no impact on the bulk ash content of shred flail treated corn stover, but the mixed in-feed baler may be able to further reduce bale heterogeneity and reduce measurement uncertainty by providing some mixing during bale formation. If the use of a shred flail is not possible, mowing the stubble negatively impacts bale ash content but positively impacts bale heterogeneity by decreasing the occurrence of rootballs. If a raking operation is necessary, the choice of a hydraulically driven basket rake over a ground-driven wheel rake drastically reduces bulk soil entrainment and slightly reduces bale heterogeneity. Overall, the findings of this research show equipment selection to have a wide range of impacts on corn stover bale quality, and special consideration should be given to equipment choice in instances where ash content is important.

Acknowledgments The authors thank Rachel Emerson, Amber Hoover, and Karen Delezene-Briggs of the Idaho National Laboratory for their dedication to sample analysis. The authors also thank Tim Clark, Bill Belden, and the equipment operators with FDC Enterprises for preparing the bales used in this work.

This work is supported by the U.S. Department of Energy, under DOE Idaho Operations Office Contract DE-AC07-05ID14517. Accordingly, the U.S. Government retains a nonexclusive, royalty-free license to publish or reproduce the published form of this contribution, or allow others to do so, for U.S. Government purposes.

U.S. Department of Energy Disclaimer This information was prepared as an account of work sponsored by an agency of the U.S. Government. Neither the U.S. Government nor any agency thereof, nor any of their employees, makes any warranty, express or implied, or assumes any legal liability or responsibility for the accuracy, completeness, or usefulness of any information, apparatus, product, or process disclosed, or represents that is use would not infringe privately owned rights. References herein to any specific commercial product, process, or service by trade name, trademark, manufacturer, or otherwise, does not necessarily constitute or imply its endorsement, recommendation, or favoring by the U.S. Government or any agency thereof. The views and opinions of authors expressed herein do not necessarily state or reflect those of the U.S. Government or any agency thereof.

Open Access This article is distributed under the terms of the Creative Commons Attribution License which permits any use, distribution, and reproduction in any medium, provided the original author(s) and the source are credited.

\section{References}

1. Perlack RD, Stokes BJ (2011) U.S. billion-ton update: biomass supply for a bioenergy and bioproducts industry. Oak Ridge National Laboratory, Oak Ridge, TN

2. Hess JR, Kenney KL, Wright CT, Perlack R, Turhollow A (2009) Corn stover availability for biomass conversion: situation analysis. Cellulose 16(4):599-619. doi:10.1007/s10570-009-9323-z

3. McKendry P (2002) Energy production from biomass (part 1): overview of biomass. Bioresour Technol 83(1):37-46. doi:10.1016/ s0960-8524(01)00118-3

4. Werther J, Saenger M, Hartge EU, Ogada T, Siagi Z (2000) Combustion of agricultural residues. Prog Energy Combust Sci 26(1):1-27

5. Weiss ND, Farmer JD, Schell DJ (2010) Impact of corn stover composition on hemicellulose conversion during dilute acid pretreatment and enzymatic cellulose digestibility of the pretreated solids. Bioresour Technol 101(2):674-678. doi:10.1016/j.biortech.2009.08. 082

6. Humbird D, Davis R, Tao L, Kinchin C, Hsu D, Aden A, Schoen P, Lukas J, Olthof B, Worley M (2011) Process design and economics for biochemical conversion of lignocellulosic biomass to ethanol. National Renewable Energy Laboratory Technical Report NREL. TP-5100-47764 
7. Kenney KL, Smith WA, Gresham GL, Westover TL (2013) Understanding biomass feedstock variability. Biofuels 4(1):111-127

8. Fang X, Jia L (2012) Experimental study on ash fusion characteristics of biomass. Bioresour Technol 104:769-774. doi:10.1016/j.biortech. 2011.11.055

9. Xiong SJ, Burvall J, Orberg H, Kalen G, Thyrel M, Ohman M, Bostrom D (2008) Slagging characteristics during combustion of corn stovers with and without kaolin and calcite. Energy Fuel 22(5):3465-3470. doi:10.1021/Ef700718j

10. Agblevor FA, Besler S, Wiselogel AE (1995) Fast pyrolysis of stored biomass feedstocks. Energy Fuel 9(4):635-640. doi:10.1021/ Ef00052a010

11. Xiong S, Öhman M, Zhang Y, Lestander T (2010) Corn stalk ash composition and its melting (slagging) behavior during combustion. Energy Fuel 24(9):4866-4871. doi:10.1021/ef1005995

12. Shinners K, Wepner A, Muck R, Weimer P (2011) Aerobic and anaerobic storage of single-pass, chopped corn stover. Bioenerg Res 4(1):61-75. doi:10.1007/s12155-010-9101-7

13. Shinners K, Boettcher G, Hoffman D, Munk J, Muck R, Weimer P (2009) Single-pass harvest of corn grain and stover: performance of three harvester configurations. Trans ASAE (Am Soc Agric Eng) 52(1):51

14. Angles MN, Reguant J, Martinez JM, Farriol X, Montane D, Salvado $J$ (1997) Influence of the ash fraction on the mass balance during the summative analysis of high-ash content lignocellulosics. Bioresour Technol 59(2-3):185-193. doi:10.1016/S0960-8524(96)00149-6

15. Zevenhoven M, Yrjas P, Skrifvars B-J, Hupa M (2012) Characterization of ash-forming matter in various solid fuels by selective leaching and its implications for fluidized-bed combustion. Energy Fuel 26(10):6366-6386. doi:10.1021/ef300621j
16. Lindström E, Öhman M, Backman R, Boström D (2008) Influence of sand contamination on slag formation during combustion of wood derived fuels. Energy Fuel 22(4):2216-2220. doi:10.1021/ef700772q

17. Landström S, Lomakka L, Andersson S (1996) Harvest in spring improves yield and quality of reed canary grass as a bioenergy crop. Biomass Bioenergy 11(4):333-341. doi:10.1016/0961-9534(96) 00041-4

18. Morissette R, Savoie P, Villeneuve J (2011) Combustion of corn stover bales in a small 146-kW boiler. Energy 4(7):1102-1111. doi: $10.3390 / \mathrm{en} 4071102$

19. Hoskinson RL, Karlen DL, Birrell SJ, Radtke CW, Wilhelm W (2007) Engineering, nutrient removal, and feedstock conversion evaluations of four corn stover harvest scenarios. Biomass Bioenergy 31(2):126-136

20. Shinners K, Bennett R, Hoffman D (2012) Single-and two-pass corn grain and stover harvesting. Trans ASABE 55(2):341-350

21. 2011 Kansas Corn County Estimates. USDA National Agricultural Statistics Service, Washington DC. http://www.nass.usda.gov/ Statistics_by_State/Kansas/.

22. Pordesimo LO, Edens WC, Sokhansanj S (2004) Distribution of aboveground biomass in corn stover. Biomass Bioenergy 26(4): 337-343. doi:10.1016/S0961-9534(03)00124-7

23. Sluiter A, Hames B, Ruiz R, Scarlata C, Sluiter J, Templeton D (2008) Determination of ash in biomass. National Renewable Energy Laboratory

24. Inc. SI (2010) JMP 9 Modeling and Multivariate Methods

25. Hess JR, Kenney KL, Ovard LP, Searcy EM, Wright CT (2009) Commodity-scale production of an infrastructure-compatible bulk solid from herbaceous lignocellulosic biomass. Idaho National Laboratory, Idaho Falls, ID 